Article

\title{
Mapping the Flow of Forest Migration through the City under Climate Change
}

\author{
Qiyao Han * and Greg Keeffe
}

School of Natural and Built Environment, Queen's University Belfast, Belfast, BT7 1NN, UK; E-Mails: qhan01@qub.ac.uk (Q.H.), g.keeffe@qub.ac.uk (G.K.)

* Corresponding author

Submitted: 24 September 2018 | Accepted: 12 October 2018 | Published: 21 February 2019

\begin{abstract}
Rapid climate change will create extreme problems for the biota of the planet. Much of it will have to migrate towards the poles at a rate far beyond normal speeds. In this context, the concept of assisted migration has been proposed to facilitate the migration of trees. Yet current practices of assisted migration focus on "where tree species should be in the future" and thus have many uncertainties. We suggest that more attention should be paid on the flow of forest migration. Therefore, this study develops a three-step methodology for mapping the flow of forest migration under climate change. Since the migration of trees depends on the activities of their seed dispersal agents, the accessibility of landscapes for dispersal agents is mainly considered in this study. The developed method combines a least-cost path model, a graph-based approach, and a circuit theory-based model. The least-cost path model is applied to map the movement of dispersal agents, based on which graph-based indices are used to evaluate the accessibility of landscapes for dispersal agents, which in turn is used as the basis for circuit theory-based modelling to map the flow of forest migration. The proposed method is demonstrated by a case study in the Greater Manchester area, UK. The resulting maps identify areas with high probability of climate-driven migration of trees.
\end{abstract}

\section{Keywords}

climate change; forest migration; urban landscape; seed dispersal

\section{Issue}

This article is part of the issue "The City of Flows: Urban Planning of Environmental Flows", edited by Rob Roggema (Cittaideale, The Netherlands/Hanze University Groningen, The Netherlands).

(C) 2019 by the authors; licensee Cogitatio (Lisbon, Portugal). This article is licensed under a Creative Commons Attribution 4.0 International License (CC BY).

\section{Introduction}

Transformation of tree species is the most important threat related with climate change (Dyderski, Paź, Frelich, \& Jagodziński, 2018). According to projections by the Intergovernmental Panel on Climate Change (IPCC, 2013), the global mean surface temperature is likely to increase $1.1-4.8^{\circ} \mathrm{C}$ relative to $1986-2005$ by the end of this century. One major consequence is that about $84 \%$ of all species have moved towards the poles to track suitable climate conditions (Thomas, 2010). Nevertheless, such movements do not guarantee their survival if they are not able to move fast enough to keep pace with the mov- ing climate, especially for those relatively immobile plant species (Jump \& Peñuelas, 2005).

Normal rates of plant movement in unfragmented habitats range from $1.7 \mathrm{~m}$ to $1500 \mathrm{~m}$ every year, whereas the rates of future climatic warming could be $3000 \mathrm{~m}$ to $5000 m$ each year (Petit, Hu, \& Dick, 2008). This implies that most plant species will lag behind future climate change (Cunze, Heydel, \& Tackenberg, 2013). Since trees are essential elements of forest ecosystems, the failure of them to track climate change will not only lead to the loss of wood resource and ecological functions but also slow the movements of animals that depend on them for habitat or food. 
Within this context, the concept of assisted migration (also called managed translocation or assisted colonisation) is gaining increased acceptance as an important strategy to facilitate natural migration. Assisted migration refers to the translocation of species or genotypes from their natural ranges to areas where future climate might be favourable (Petit et al., 2008). In the face of ongoing climate change, assisted migration has already been incorporated into forest management in many regions and countries. In England, the Forestry Commission recommends that "at least one source of seed from slightly warmer climates sources from two to five degrees of latitude further south than the site is used". In Canada, several provinces have modified their seedtransfer guidelines in anticipation of moderate climate warming. Despite the widespread implementation of assisted migration, there is a considerable uncertainty in the projections of future species ranges due to the large uncertainty and variability among the projections of climate change (Lindner et al., 2014), which results in a risk of moving tree species too far or not far enough (Ferrarini et al., 2016).

To address this problem, we suggest that more efforts should be made on understanding the process (flow) of forest migration rather than predicting "where species should be in the future". Since migration of trees is a continuing process that does not rely on their future ranges, a "process-oriented" solution avoids the projections of future climate, and thus might be more robust to climate change than current "goal-oriented" practices. Moreover, understanding the process of forest migration enables us to identify critical locations along the process for accommodating relocated tree species, so that from those areas the species could expand further to colonise other suitable habitats (Pereira, Saura, \& Jordán, 2017). Also, it may be easier for managers to focus on the process of forest migration, rather than to maintain a relocated species at a given site, especially in urban areas where human activity is intense and implementing large continuous reserves is not possible.

There are several methods available to map ecological processes and flows in heterogeneous landscapes (Adriaensen et al., 2003; Cushman et al., 2013; Lechner, Doerr, Harris, Doerr, \& Lefroy, 2015; Rayfield, Fortin, \& Fall, 2011; Saura, Vogt, Velázquez, Hernando, \& Tejera, 2011). Of all these methods, circuit theory (McRae \& Beier, 2007) has been widely applied in recent years because of its ability to model random dispersal patterns and to predict all possible movement pathways across a landscape simultaneously. Circuit theory treats the landscape as a conductive surface within an electrical circuit, characterising resistance/conductance to movement for every raster grid cell, considering current flow as analogous to movement patterns across the landscape. Recently, many methods have been developed to model climate-driven migration of species based on circuit theory (e.g., Lawler, Ruesch, Olden, \& McRae, 2013; Littlefield, McRae, Michalak, Lawler, \&
Carroll, 2017). However, most of them focus on the movement of active dispersers (animals), characterising resistance/conductance based on specific landscape features related to habitat quality or the intensity of human modification (e.g., land cover type, road density, and housing density), and thus may be less suitable for the migration of tree species that depends on passive seed dispersal.

Successful forest migration depends on effective seed dispersal between forest fragments, which is affected by the ways in which seed dispersal agents move and interact with the landscape (Carlo, Aukema, \& Morales, 2007). Hence, the movement of dispersal agents should be taken into account for the analysis of forest migration. It should be noted that, for the aim of this study, we only focus on animal-dispersed tree species, since water- or wind-dispersed species can be carried for long distances and thus may have a better chance of survival. From this perspective, the spatial pattern of a landscape is actually of great importance because it directly influences the accessibility of the landscape for dispersal agents, whereas landscape features related to habitat quality or human modification may be of limited value. Therefore, a new method is needed for mapping the flow of forest migration from the perspective of seed dispersal.

To this end, this study develops a three-step methodology combining a least-cost path (LCP) model and a graph-based approach with the circuit theory. The LCP model is applied to map the movement of dispersal agents in the landscape, based on which graph-based indices are used to evaluate landscape accessibility for dispersal agents, which in turn is used as the basis for circuit theory-based modelling to map the flow of forest migration under climate change. Since the focus of this study is on seed dispersal, the behaviour of dispersal agents is mainly considered; other biotic or abiotic factors such as soil type, plant diversity, or interspecific competition are excluded. In particular, the habitat and home-range scale of dispersal agents are simultaneously considered in this method to account for their multi-scale behaviours. The proposed method is demonstrated by a case study in the Greater Manchester area, UK.

\section{Study Area and Data}

Greater Manchester is a metropolitan region of approximately 127,600 hectares in North West England, UK (Figure 1a). The region comprises ten districts: Bolton, Bury, Manchester, Oldham, Rochdale, Stockport, Tameside, Trafford, Wigan, and Salford. The total forest area in Greater Manchester is about 4695 hectares, representing $3.7 \%$ of the land area (Figure $1 \mathrm{~b}$ ). Broadleaved forests are the dominant woodland type representing $74.6 \%$ of all woodlands, followed by mixed forests $8.0 \%$ and conifer forests $7.8 \%$.

The Ordnance Survey Master Map of Greater Manchester (provided by Digimap at digimap.edina.ac.uk) is used as the land-cover data source for the study. To avoid 
(a)

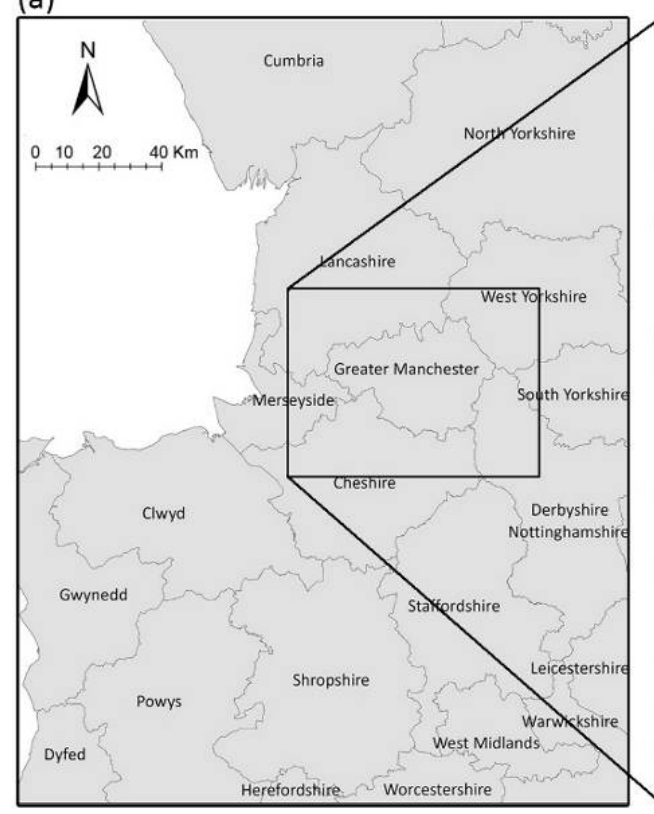

(b)

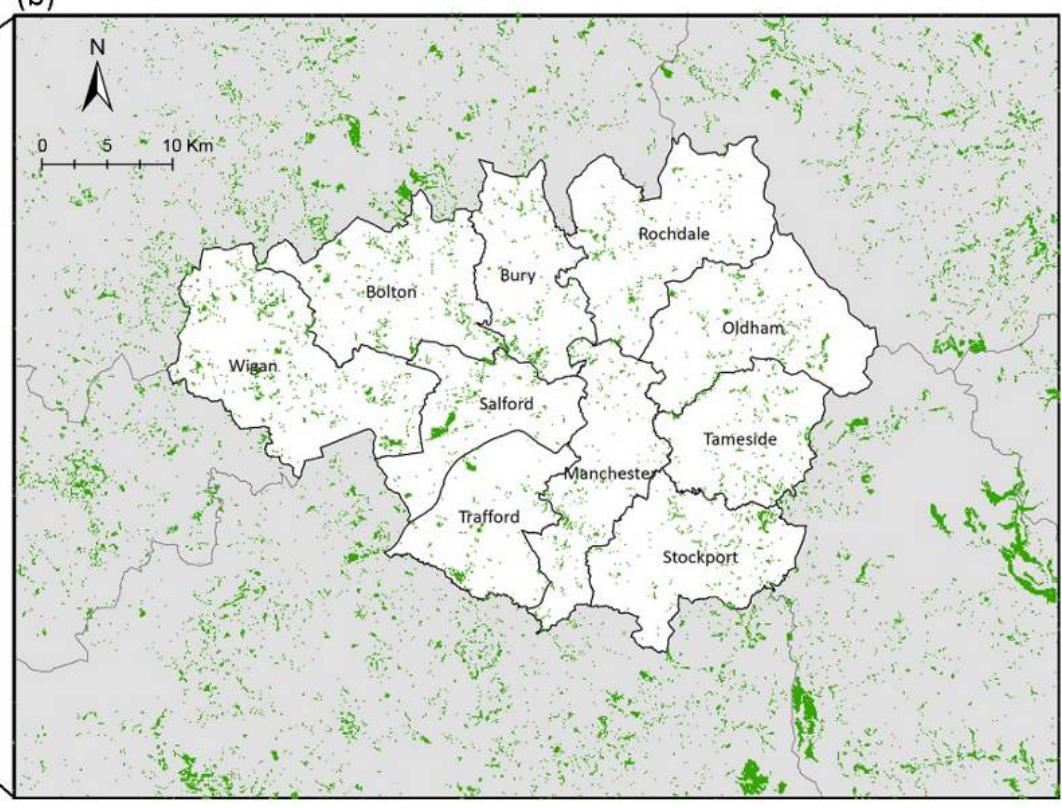

Figure 1. The study area: (a) the location of the study area; (b) woodlands in the study area.

the bias that would result from selecting a study area with merely administrative delimitations, the land-cover data are extended into the peripheral regions surrounding Greater Manchester. The 2010 topography layer (vector map) in the Ordnance Survey Master Map gives a comprehensive view of 13 broad land-cover types in the study area. In addition, to compare the resulting map from the proposed method with that from other circuit theory-based methods which focus on habitat quality or human modification, the Greenspace Layer (with detailed land use categories which captures the major aspects of human modification) in the Ordnance Survey Master Map is used to classify urban landscapes as: (1) natural, with a low intensity of human modification (e.g., natural woodland); (2) semi-natural, with an intermediate intensity of human modification (e.g., camping park, cemetery, golf course, public park or garden); and (3) manmade, with a high intensity of human modification (e.g., transport, bowling green, sports facility).

Although tree species can be dispersed by various dispersal agents, this study mainly considers frugivorous birds as effective dispersal agents, given their contribution to long-distance seed dispersal, which is highly important for climate-driven range shifts of trees (de Casas, Willis, \& Donohue, 2012; Nathan, 2006). Compared with other frugivores, birds have relatively large habitats and home ranges and are much more effective for seed dispersal: rodents-such as mice and squirrels-have restricted dispersal distances and act mainly as seed predators (Hougner, Colding, \& Söderqvist, 2006; Wenny, 2000); and even for some "wind dispersed" seeds, their large-scale dispersion is due to birds (Wilkinson, 1997). For the study of Greater Manchester, Eurasian jay (Garrulus glandarius) is selected as the main dispersal agent. Eurasian jay is a prevalent and probably the most active seed dispersal agent for many tree species that need to migrate through Greater Manchester in this century (Gómez, 2003; Pons \& Pausas, 2007), such as lodgepole pine (Pinus contorta), sweet chestnut (Castanea sativa), sessile oak (Quercus petraea), beech (Fagus), and Scots pine (Pinus sylvestris; see the Forestry Commission at forestry.gov.uk/fr/infd-837f9j). The large habitat and home-range size, as well as flight distance of the bird contribute to the high migration rates of many tree species (Cunze et al., 2013). Table 1 shows the key parameters of Eurasian jays in relation to their seed dispersal ability. The spatial records of Eurasian jays are obtained from the UK's NBN Atlas (nbnatlas.org).

For the propose of this study, climate change is considered as the main factor shaping tree species distributions in the future. We use the average mean temperature from 1970 to 2000 with a spatial resolution of 10 minutes (approximately $340 \mathrm{~km}^{2}$ ) to obtain the regional temperature gradients in the study area. The cli-

Table 1. Key parameters about the dispersal ability of Eurasian jays, obtained from Conway and Fuller (2010), Dyer (1995), Gómez (2003) and Rolando (1998).

\begin{tabular}{llr}
\hline Spatial scale & Area & Dispersal distance \\
\hline Habitat & $\geq 4 \mathrm{ha}$ & $\leq 1 \mathrm{~km}$ \\
Home range & $\geq 10.7 \mathrm{ha}$ & $1 \mathrm{~km}-5 \mathrm{~km}$ \\
\hline
\end{tabular}


mate data are downloaded from the WorldClim Version2 (Fick \& Hijmans, 2017).

\section{Methods}

The developed method is a three-step mapping process: (1) identifying landscape networks for dispersal agents (Eurasian jays) based on least-cost modelling; (2) assessing landscape accessibility for dispersal agents based on graph analyses; and (3) mapping the flow of forest migration based on circuit theory. The following will go through each of these steps in detail. Figure 2 is an illustration of the mapping process.

\subsection{Step 1: Identifying Landscape Networks}

This study uses a hierarchical approach to map the movement of dispersal agents, given that animals experience their landscape as a mosaic of patches at multiple scales nested within each other (Holling, 1992). Since the case study is a metropolitan region, only the habitat and home-range scale of Eurasian jays are considered; other scales are either too small in time or too big in space for the study.

\subsubsection{Habitat Network}

The landscape network at habitat scale (hereafter simply referred to as habitat network) provides animals ac- cess to food resources on a daily basis (Holling, 1992). It comprises habitat patches that serve as resources and paths which support the movements of animals among resources.

To identify habitat patches, the vector map of land cover is converted to a raster-format map, in which landcover types are reclassified as either habitat or nonhabitat area for dispersal agents. For the aim of this study, all the woodlands, including broadleaved, coniferous and mixed forests, are selected as suitable for habitat. After that, we change the resolution of the habitat map based on the minimum size (4ha) of habitat utilised by jays, aggregating small, scattered habitat fragments into large, contiguous habitat patches (Figure 2a). This is because animals utilise their habitats with species-specific grain size and may occupy habitat patches which contain non-habitat fragments (Holling, 1992). Cells are assigned to the habitat class when at least $30 \%$ area inside the cell is woodland (Andrén, 1994; Freemark \& Collins, 1992). Specifically, hexagonal grids are used to represent habitat maps for the birds, rather than frequently-used rectangular grids, considering their advantages in modelling movement paths (Birch, Oom, \& Beecham, 2007). ArcGIS 10.4 software is used for the identification of patches.

Since the dispersal probability between habitats is inversely related to the least-cost distance between them (Peña-Domene, Minor, \& Howe, 2016), the LCP model is applied to map the paths between habitats (Figure $2 \mathrm{~b}$ ). The LCP model uses a raster-based optimi-

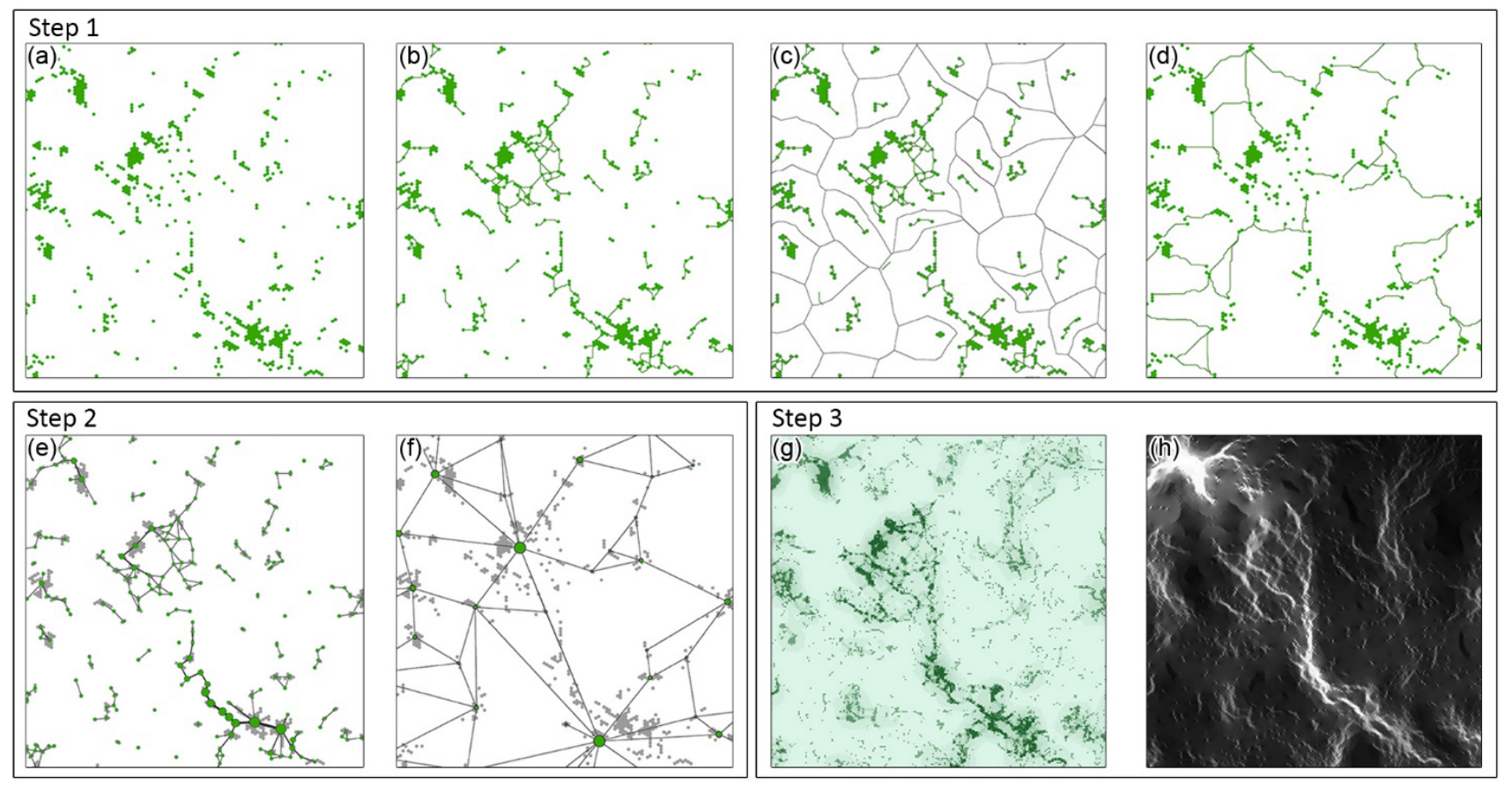

Figure 2. An illustration of the mapping process. Step 1: (a) identify habitat patches; (b) map LCPs between habitats; (c) identify home ranges by grouping connected habitat patches; (d) map LCPs between home ranges. Step 2: (e) assess habitat accessibility based on graph analyses; ( $f$ ) assess home range accessibility based on graph analyses. Step 3: (g) create a conductance surface for circuit modelling based on landscape accessibility (dark green areas are high conductance to movements, while light green areas are low conductance); (h) map the flow of forest migration (white areas) by circuit theory-based modelling. 
sation algorithm to identify the single most optimal path between patches, in terms of cumulative land-cover resistance (e.g., energetic cost, difficulty, or perceived risk; Watts et al., 2010), based on an assumption that animals have accurate cognitive maps of their home ranges and thus tend to follow the optimal paths (Hovestadt, Bonte, Dytham, \& Poethke, 2012). In the study of Greater Manchester, the resistance values of the 13 land-cover types for Eurasian jays are obtained by habitat suitability modelling.

Habitat suitability modelling provides a more objective approach for evaluating resistance values than commonly-used expert-based approaches (Milanesi et al., 2017; Stevenson-Holt, Watts, Bellamy, Nevin, \& Ramsey, 2014). It calculates the habitat suitability in$\operatorname{dex}$ (HSI) scores of non-habitat areas to infer land-cover resistance values, given that the spatial records of a species in non-habitat areas are related to its preference in movements (Stevenson-Holt et al., 2014). We use the MaxEnt software to conduct habitat suitability modelling (Phillips, Dudík, \& Schapire, 2017). The spatial records of Eurasian jays from 2005 to 2015 and the 2010 land-cover raster map (with a resolution of $100 \mathrm{~m}$ to match the spatial accuracy of the jay records) are used as input data. All habitat areas (woodlands) are removed from the land-cover map to prevent their incorporation in the model. At the same time, all areas over $500 \mathrm{~m}$ from roads are also removed to account for sampling bias towards accessible areas (Warton, Renner, \& Ramp, 2013). This leaves a total of 148 records of Eurasian jays that are within the remaining areas for habitat suitability modelling. The output HSI scores (in a logistic format) from MaxEnt indicate the probability of a species' occurrence within each land-cover type, ranging from 0 to 1. To obtain land-cover resistance values, the HSI scores are reversed to a range of $0-100$ by using $(1-\mathrm{HSI}) * 100$. Woodlands are given a value of 1 to account for their suitability for habitat.

Based on the resistance values, the LCP tool in Graphab software (Foltête, Clauzel, \& Vuidel, 2012) is applied to create edge-to-edge dispersal paths between habitats, as well as the corridors associated to the paths. The distance threshold of the dispersal paths is determined by the maximum daily dispersal distances of jays $(1 \mathrm{~km})$.

\subsubsection{Home-Range Network}

While the inter-patch movements at habitat scale contribute to daily seed dispersal, the long-distance dispersal $(>1 \mathrm{~km})$ of seeds, which facilitates the migration of trees over wider spatial extents, depends on the movements of dispersal agents at their annual homerange scale (Hougner et al., 2006; McCarthy-Neumann \& Ibáñez, 2012; Rayfield et al., 2016).

The identification of home ranges (foraging areas) is based on the above mapping of habitat networks. In highly fragmented landscapes, animals that cannot find habitat patches large enough to support their survival may be able to overcome short distances through nonhabitat areas and include neighbouring patches within their range of movement to supply their resource needs (Galpern, Manseau, \& Fall, 2011; Kang, Lee, \& Park, 2012). Therefore, the home range of Eurasian jays is composed of a cluster of functionally connected habitat patches (an isolated patch makes up a home range itself), which could support their minimum resource requirement (minimum home-range size, 10.7 ha; Figure 2c). The long-distance dispersal paths between home ranges are mapped by LCP modelling (Figure $2 \mathrm{~d}$ ), using the landcover resistance values previously obtained. The distance threshold of the paths is determined by the maximum distance $(5 \mathrm{~km})$ that jays could move in their search for new home ranges.

\subsection{Step 2: Assessing Landscape Accessibility}

Since animals experience their landscapes at multiple scales and make different decisions at each scale, the presence of dispersal agents (the probability of seed dispersal) at a given location is based on resource accessibility at multiple scales, especially in fragmented landscapes (Boscolo \& Metzger, 2009). Landscape accessibility is determined by patch area and inter-patch connections (Boscolo \& Metzger, 2011). In this respect, graphbased indices are especially suitable for assessing accessibility because they can integrate both patch area and inter-patch connections in one measure. Graph analysis has been shown to be an effective way of representing complex landscape structures (e.g., Kong, Yin, Nakagoshi, \& Zong, 2010), performing connectivity evaluations (e.g., Urban \& Keitt, 2001), and modelling species occurrence (e.g., Awade, Boscolo, \& Metzger, 2011). It transforms the landscape into a planar graph, in which patches are represented as nodes and the paths between them are expressed as links. In general, the area of each patch is taken as the attribute of its corresponding node, and the distance of each path is assigned to the link's attribute as well.

In this study, two graph-based connectivity indices, the probability of connectivity (PC; Saura \& PascualHortal, 2007) and the integral index of connectivity (IIC; Pascual-Hortal \& Saura, 2006), are used to assess landscape accessibility for Eurasian jays at habitat and homerange scale, respectively (Figures $2 \mathrm{e}$ and $2 \mathrm{f}$ ). The main difference between PC and IIC is that the former is a probabilistic index, where the length of each dispersal path is taken into account to calculate inter-patch connection probabilities, while the latter is a binary index, which focuses on the topological distances (in terms of the number of paths) between patches, with the degree of connectivity decreasing as the topological distance gets larger.

The PC index relates significantly to the actual movement and occurrence patterns of species at habitat scale (Awade et al., 2011; Pereira et al., 2017), especially for 
seed dispersal, because the probability of effective seed dispersal is a decreasing function of inter-patch distance (Peña-Domene et al., 2016). The accessibility of each habitat or path for jays can be inferred from a quantification of its contribution to the overall connectivity (PC value) of the home range that the patch or path belongs to. To do this, we first calculate the PC index for the home range, and then remove each patch or path and recalculate the PC index. The percentage of connectivity loss indicates the individual contribution of each patch or path. Patches with a high contribution are believed to be key hubs for seed dispersal and have a high frequency of visitation by dispersal agents (Carlo et al., 2007; Hock \& Mumby, 2015). The calculation of the PC index is conducted with the Graphab software, in which a few parameters are set to obtain a $5 \%$ probability of dispersal corresponding to the maximum daily dispersal distance $(1 \mathrm{~km})$ of jays.

Along with the calculation of the PC index at habitat scale, the IIC index is used to evaluate the accessibility of each home range, within which all habitat patches are conceptualised as a single node. The IIC index provides a rough description of inter-patch connections and has been shown to better relate to the functional connectivity among home ranges than PC (Decout, Manel, Miaud, \& Luque, 2012). Similarly, the accessibility of each home range is evaluated by a measurement of its contribution to the overall connectivity (IIC value) of the home-range network, using the Graphab software.

\subsection{Step 3: Mapping the Flow of Forest Migration}

In the final step, a circuit theory-based method is applied to model the flow of forest migration based on the understanding of landscape accessibility for dispersal agents. A conductance surface which represents the permeability of landscapes to forest migration and sets of sources and targets that determine migration directions are used as inputs for the modelling. Accordingly, the potential migration patterns of trees are predicted as the electrical current flows from sources to targets through the conductance surface.

The conductance surface is the basis for the modelling, which relates the above assessment of landscape accessibility to the migration process of trees. In this study, the conductance value of each land-cover cell is determined by its accessibility at multiple scales, based on an assumption that landscapes with higher accessibility for dispersal agents might have a higher probability of seed dispersal and thus are more permeable to the migration of trees (Figure 2g). Given the interactions between landscapes at different scales (Awade et al., 2011), the conductance surface is created by multiplying the results of accessibility assessment at both habitat and home-range scale. ArcGIS 10.4 software is used to calculate the conductance surface. Since landscape permeability is a relative measure, the conductance values are nor- malised to a range of 1-100, with higher values indicate greater ease of movement.

To avoid the uncertainty in the projections of future climate change, the directions of forest migration are predicted by the historical climate gradients in the study area, according to an assumption that spatial temperature change is relatively uniform in direction. This assumption is based on evidence that temperature gradients over extensive geographical areas (from several kilometres to several hundred kilometres) are driven largely by topography (Daly, 2006). Since topography is constant over time, it can be expected that the directions of these climate gradients will not change substantially. This same assumption has been used in many studies for identifying corridors for climate-driven movements (e.g., Cushman et al., 2013; McGuire, Lawler, McRae, Nuñez, \& Theobald, 2016; Nuñez et al., 2013). As a result, we use the temperature gradients in the study area to identify pairs of source and target forests (woodlands bigger than 100ha), that, if connected, would allow trees to move from warmer to cooler areas. The advanced mode in Circuitscape software is applied to model the flow of forest migration between each pair of forests (Figure 2h).

\section{Results}

\subsection{Landscape Networks}

At habitat scale, the aggregation of habitat areas yields 1886 habitat patches for Eurasian jays, covering 5.3\% of the total study area (Figure 3a). These patches are connected by 1808 dispersal paths in the LCP model. The land-cover resistance values for the LCP model are derived from the habitat suitability modelling in MaxEnt. Table 2 shows the HSI score for each land-cover type and the corresponding resistance value. After that, all habitat patches are divided into 551 separate components of interconnected patches. According to the minimum home-range size of Eurasian jays, 285 components are identified as annual home ranges, accounting for $94 \%$ of all habitat patches. These home ranges are connected by 554 long-distance dispersal paths in the LCP model (Figure $3 b$ ).

\subsection{Landscape Accessibility}

The result of graph analyses is an understanding of which patches in the landscape are expected to be accessible for dispersal agents. Figure 4 illustrates the relative accessibility of individual habitats and home ranges. Patches with high values are critical for maintaining landscape connectivity and therefore can be regarded as key hubs for seed dispersal. As shown in Figure $4 b$, at home-range scale, only a handful of habitats are responsible for a disproportionate contribution to the overall connectivity (IIC value) of the landscape, and therefore should be given more attention for protection. 

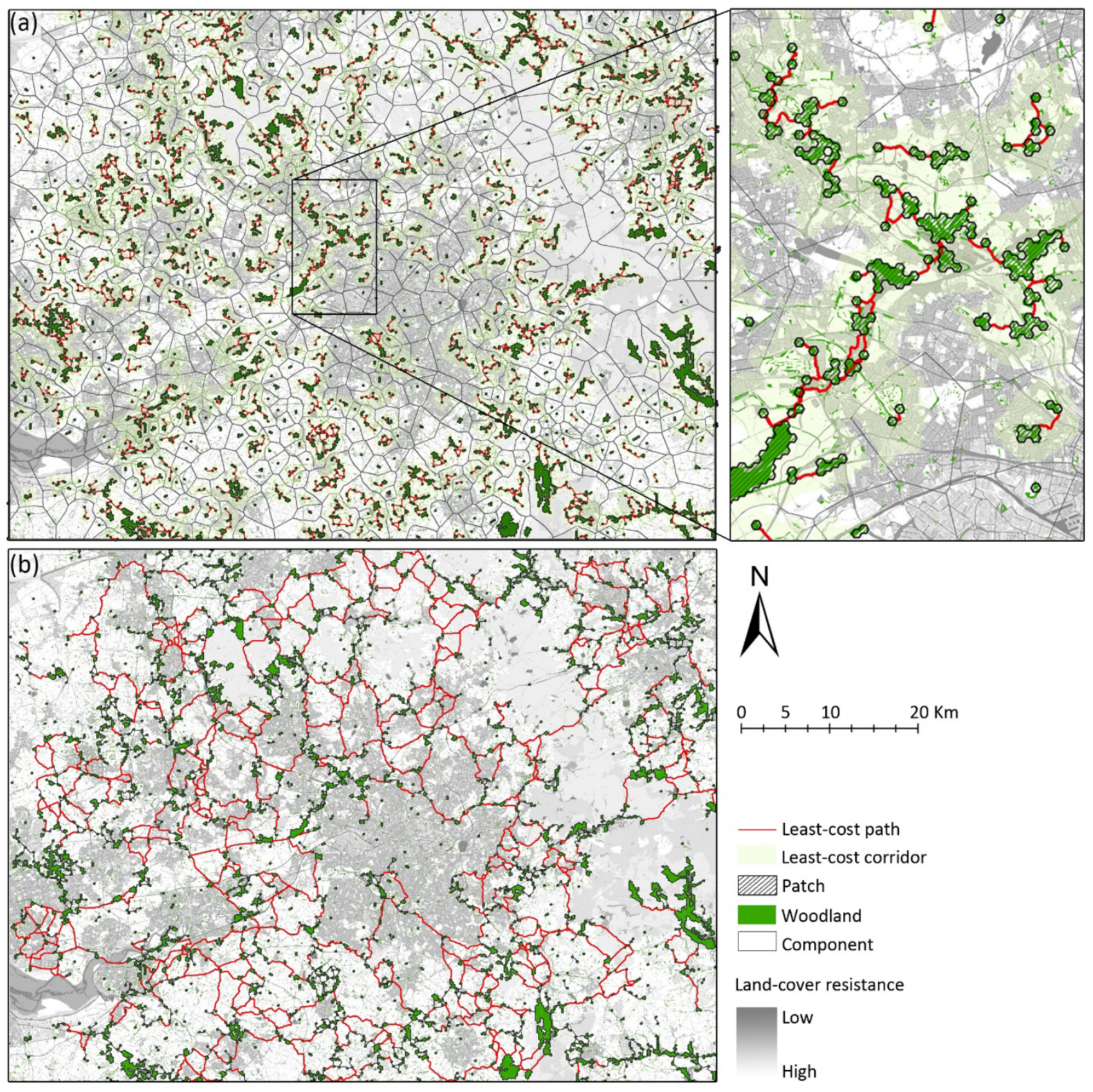

Figure 3. Landscape networks for Eurasian jays: (a) habitat network; (b) home-range network.

Table 2. HSI scores obtained from MaxEnt and the corresponding resistance values.

\begin{tabular}{lll}
\hline Land-cover type & HSI score & Resistance value \\
\hline Buildings & 0.46 & 54 \\
Health & 0.43 & 57 \\
Marsh & 0.43 & 57 \\
Residential land & 0.47 & 53 \\
Agricultural land & 0.4 & 60 \\
Orchard & 0.43 & 57 \\
Roads & 0.69 & 31 \\
Rock & 0.5 & 50 \\
Rough Grassland & 0.41 & 59 \\
Scrub & 0.67 & 33 \\
Urban & 0.43 & 57 \\
Water & 0.85 & 15 \\
Woodland & N/A & 1 \\
\hline
\end{tabular}



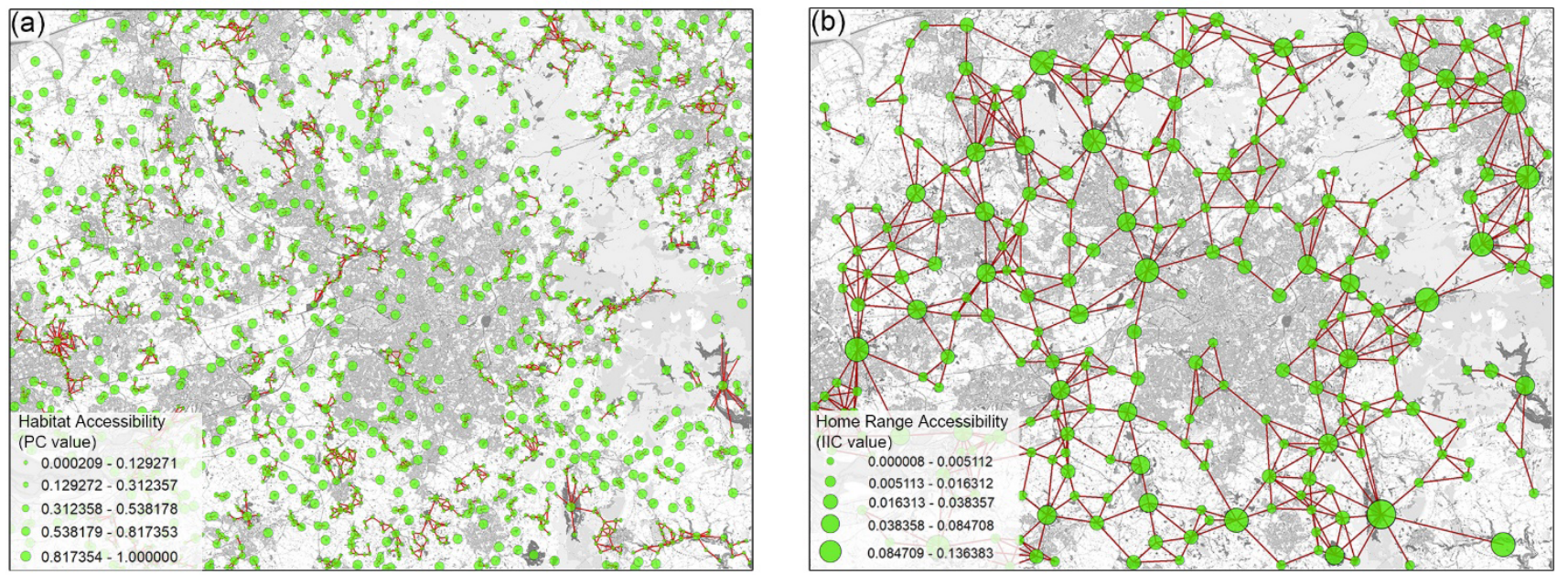

Figure 4. Landscape accessibility for Eurasian jays: (a) habitat accessibility (PC value); (b) home-range accessibility (IIC value).

\subsection{Forest Migration Flows}

In the final step, flows of forest migration are modelled as the electrical current flows from source to target forests. The resulting current maps (Figure 5) capture the broadscale migration pattern of trees, with high current values (amps) indicating a relatively high probability of movement. All the current maps are then integrated to generate a cumulative current map (Figure 6) for identifying critical areas for forest migration where conservation efforts should be concentrated. Sites with higher values are suggested to be a high priority for protection or improvement, as they have a great impact on the process of forest migration. In these areas, a habitat loss would impede migration speed or modify migration pattern, whereas maintaining or enhancing habitat quality would guarantee or facilitate this ecological process. However, areas with lower values could be considered to be low in priority for protection as they have little contributions to forest migration, when only the seed dispersal activities of Eurasian jays are considered. As shown in Figure 6, locations that are critical for forest migration is likely to be concentrated in a few areas. For example, in Bolton, most areas are considered important for the flow of forest migration, while greenspaces in Rochdale and Oldham contribute little to this ecological process. This allows implementing a more efficient measure for forest management to cope with the warming climate.

With an aim to illustrate the difference between passive and active migration, we compare the resulting map generated with our seed dispersal-based method with a map of ecological flows based on the intensity of human modification of the landscape (Figure 6 versus Figure 7). Considering seed dispersal in circuit theorybased modelling substantially shifts and constrains the priority areas for movements to a smaller proportion of the landscape than when human modification is considered. Many areas that emerge as important for passive tree migration in our resulting map are less important for active species' movements that based on the intensity of human modification. Our results illustrate that migration flows that depend on passive dispersal may differ from those that rely on active dispersal.

\section{Discussion and Conclusion}

This study develops a sophisticated method to map the flow of forest migration under climate change. The resulting map of Greater Manchester not only identifies the functional connections between urban landscapes that may be able to conduct flows of forest migration, but also highlights important areas in the study area that could support the migration of trees. This allows designers to re-visualise the landscape as a series of interconnected flow channels, which in turn allows for a more piecemeal form of landscape design to optimise urban landscapes for climate adaptation. In this respect, this method would be especially important for the areas where human activity is intense and implementing large continuous reserves is not possible.

This study avoids a tree species-specific perspective but focuses on the movement of seed dispersal agents. This is because a tree species-specific approach requires an explicit assessment of many biotic and abiotic factors, such as species density, life-history traits, interspecific competition, elevation, land use, soil type and moisture. Such an approach is useful, especially for species of particular ecological importance at a local scale. However, the complexity of these factors makes it is difficult, if not impossible, over extensive geographical areas, especially under a changing climate. Moreover, our purpose here is not to provide a detailed assessment for a single tree species but to capture broad-scale potential movements and, specifically, to provide more general guidance for planning or designing urban landscapes for forest migration. In this respect, the method based on seed dispersal is more efficient and general because it could capture the migration pattern of a set of tree species dispersed by a 

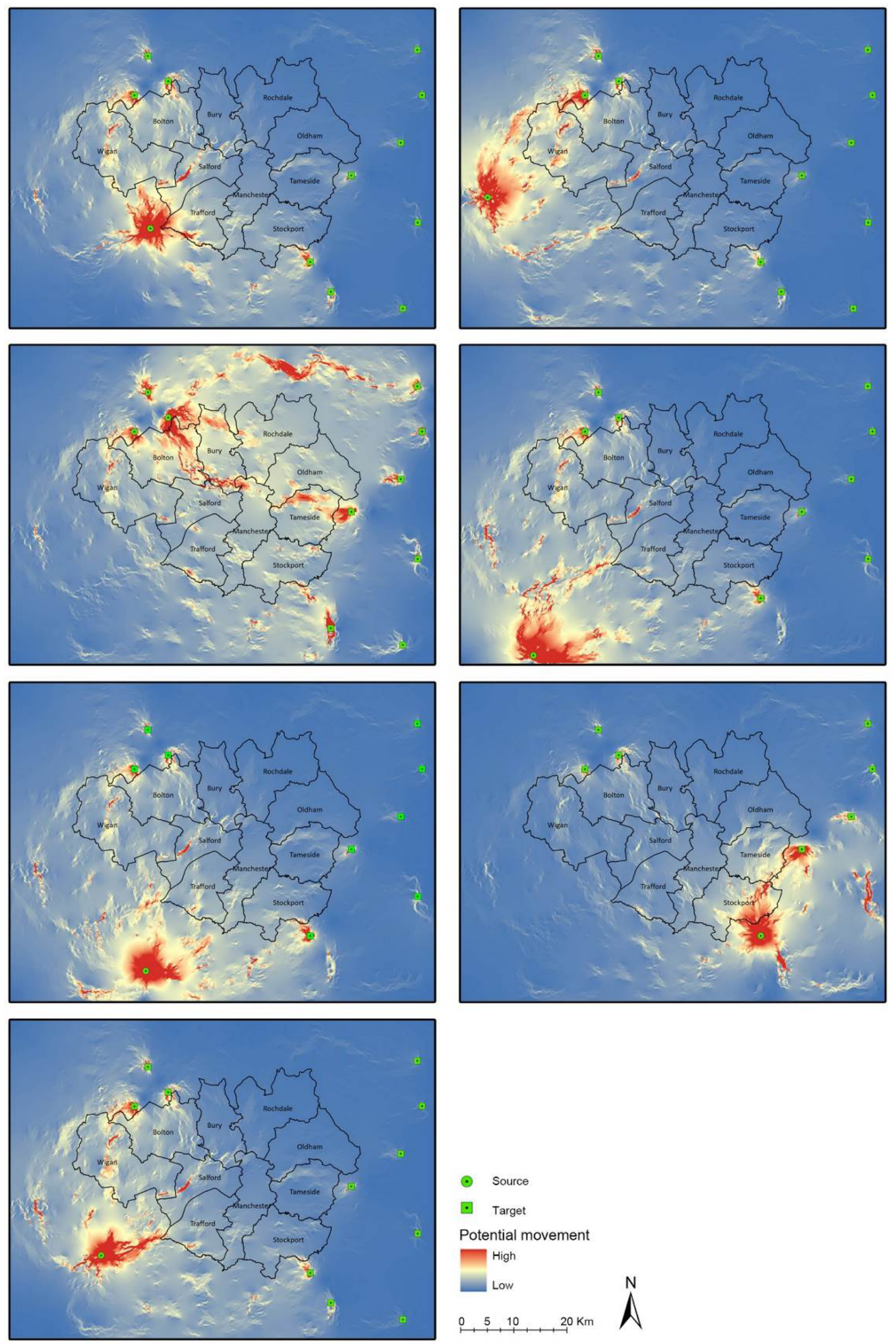

Figure 5. The flows of forest migration between different pairs of forests. 

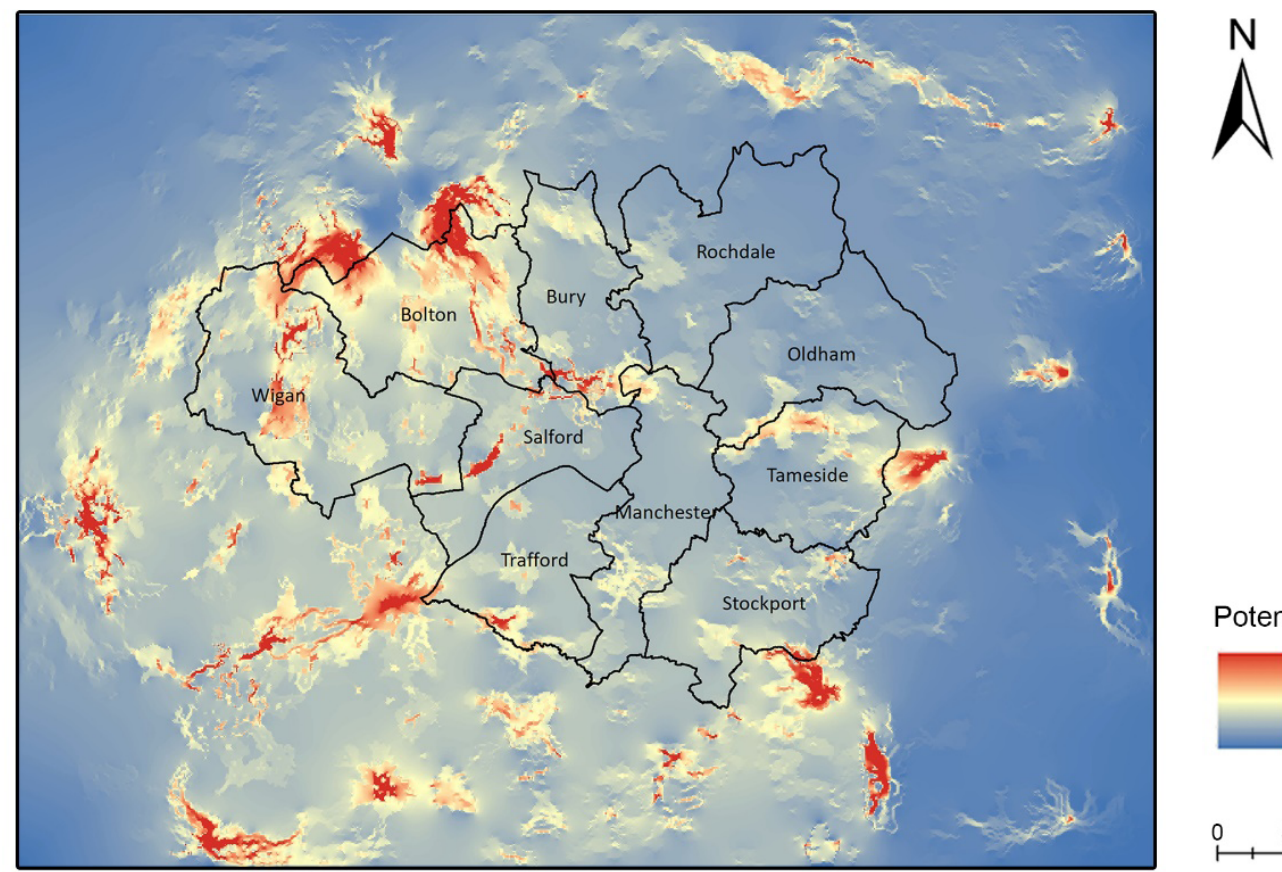

Potential movement

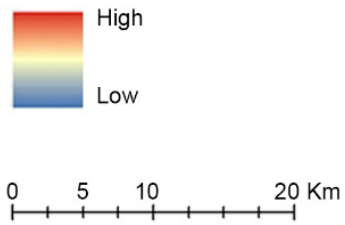

Figure 6. The integrated flows of forest migration in the study area.
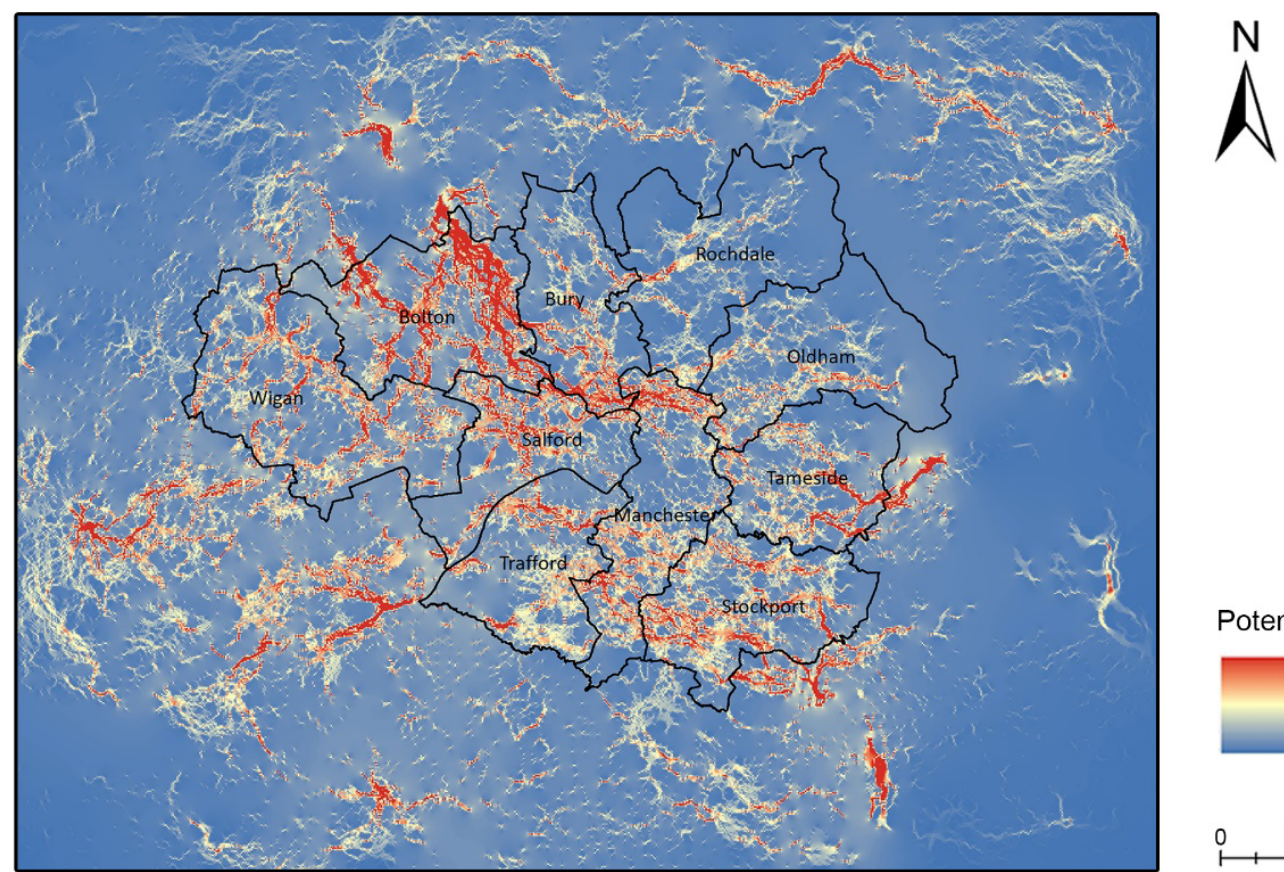

Potential movement

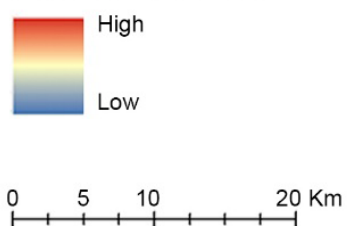

Figure 7. The flows of active migration based on the intensity of human modification.

specific dispersal agent. Nevertheless, this method could be complemented with species-specific models for tree species with specialised habitat requirements.

This method evaluates landscape accessibility for dispersal agents based on graph analyses. A more sophisticated approach would be a field-based analysis of dispersal agents. However, the data required for the analysis is not commonly available, particularly for bird species over a large spatial extent, and observing bird activities is beyond the scope of this research. Moreover, a distinction is difficult to made between the presence of a bird in a landscape that can be explained by a habitat function and the presence due to a dispersal function. In other words, capture of a bird in a particular location does not necessarily indicate that it is foraging in that area, rather it may simply be moving through the area to a different location (Aborn \& Moore, 1997). Therefore, a graph-based approach might be more suitable and practical for analysing the activities of dispersal agents. Particularly, this method offers an additional advantage: it allows a precise evaluation of the potential benefits and efficiency of adding new patches (through forestation or 
restoration programs) in the landscape matrix to favour the movements of dispersal agents and thereby to facilitate the migration of trees.

Furthermore, this method avoids the uncertainties associated with the projections of climate change. Rather than connecting current habitat areas to areas predicted to have suitable climate conditions in the future, our method connects forests based on general climate patterns, assuming that temperature gradients are conserved in a changing climate. In this way, this method could be more robust to future climate change.

Although this mapping method provides certain advantages, it is based on several simplifying assumptions, and therefore has two limitations. On one hand, since this method uses temperature gradients at a large scale, it might miss some of the more localised climate patterns (e.g., urban heat island effect) and thus cannot be applied to a small spatial extent or locations with unique climatic gradients. On the other hand, Eurasian jays are assumed to be the main dispersal agents in the study, although there are a number of seed dispersal agents available in Greater Manchester, for example, Eurasian siskins, coal tits and grey squirrels. As different dispersal agents (with different dispersal abilities) may respond very differently to the landscape (Saunders, Hobbs, \& Margules, 1991), results presented in this study do not cover all the important greenspaces that could facilitate forest migration. For future studies of Greater Manchester, it would be desirable to take other seed dispersal agents into account.

\section{Acknowledgments}

Qiyao Han is funded by China Scholarship Council of Chinese government. The authors would like to thank Gary Archibald Boyd, Gul Kacmaz Erk, Helen Roe and Paul Caplat for their comments and suggestions.

\section{Conflict of Interests}

The authors declare no conflict of interests.

\section{References}

Aborn, D. A., \& Moore, F. R. (1997). Pattern of movement by summer tanagers (Piranga Rubra) during migratory stopover: A telemetry study. Behaviour, 134(13), 1077-1100.

Adriaensen, F., Chardon, J. P., De Blust, G., Swinnen, E., Villalba, S., Gulinck, H., \& Matthysen, E. (2003). The application of 'least-cost' modelling as a functional landscape model. Landscape and Urban Planning, 64(4), 233-247.

Andrén, H. (1994). Effects of habitat fragmentation on birds and mammals in landscapes with different proportions of suitable habitat: A review. Oikos, 71(3), 355-366.

Awade, M., Boscolo, D., \& Metzger, J. P. (2011). Us- ing binary and probabilistic habitat availability indices derived from graph theory to model bird occurrence in fragmented forests. Landscape Ecology, 27(2), 185-198.

Birch, C. P. D., Oom, S. P., \& Beecham, J. A. (2007). Rectangular and hexagonal grids used for observation, experiment and simulation in ecology. Ecological Modelling, 206(3), 347-359.

Boscolo, D., \& Metzger, J. P. (2009). Is bird incidence in Atlantic forest fragments influenced by landscape patterns at multiple scales? Landscape Ecology, 24(7), 907-918.

Boscolo, D., \& Metzger, J. P. (2011). Isolation determines patterns of species presence in highly fragmented landscapes. Ecography, 34(6), 1018-1029.

Carlo, T. A., Aukema, J. E., \& Morales, J. M. (2007). Plantfrugivore interactions as spatially explicit networks: Integrating frugivore foraging with fruiting plant spatial patterns. In A. J. Dennis, E. W. Schupp, R. J. Green, \& D. A. Westcott (Eds.), Seed dispersal: Theory and its application in a changing world (pp. 369-390). Wallingford: $C A B$ International.

Conway, G. J., \& Fuller, R. J. (2010). Multi-scale relationships between vegetation pattern and breeding birds in the Upland Margins (ffridd) of North Wales (BTO Research Report no. 566). Norfolk: British Trust for Ornithology.

Cunze, S., Heydel, F., \& Tackenberg, O. (2013). Are plant species able to keep pace with the rapidly changing climate? PLoS One, 8(7), e67909.

Cushman, S. A., Beier, P., McRae, B., Adriaensen, F., Shirley, M., \& Zeller, K. (2013). Biological corridors and connectivity. In D. W. Macdonald \& K. J. Willis (Eds.), Key topics in conservation biology 2 (pp. 384-404). Hoboken, NJ: Wiley-Blackwell.

Daly, C. (2006). Guidelines for assessing the suitability of spatial climate data sets. International Journal of Climatology, 26(6), 707-721.

de Casas, R. R., Willis, C. G., \& Donohue, K. (2012). Plant dispersal phenotypes: A seed perspective of maternal habitat selection. In Dispersal ecology and evolution (pp. 171-184). Oxford: Oxford University Press.

Decout, S., Manel, S., Miaud, C., \& Luque, S. (2012). Integrative approach for landscape-based graph connectivity analysis: A case study with the common frog (Rana temporaria) in human-dominated landscapes. Landscape Ecology, 27(2), 267-279.

Dyderski, M. K., Paź, S., Frelich, L. E., \& Jagodziński, A. M. (2018). How much does climate change threaten European forest tree species distributions? Global Change Biology, 24(3), 1150-1163.

Dyer, J. M. (1995). Assessment of climatic warming using a model of forest species migration. Ecological Modelling, 79(1), 199-219.

Ferrarini, A., Selvaggi, A., Abeli, T., Alatalo, J. M., Orsenigo, S., Gentili, R., \& Rossi, G. (2016). Planning for assisted colonization of plants in a warming world. Scientific Reports, 6, 28542. 
Fick, S. E., \& Hijmans, R. J. (2017). WorldClim 2: New 1-km spatial resolution climate surfaces for global land areas. International Journal Of Climatology, 37(12), 4302-4315.

Foltête, J.-C., Clauzel, C., \& Vuidel, G. (2012). A software tool dedicated to the modelling of landscape networks. Environmental Modelling \& Software, 38, 316-327.

Freemark, K., \& Collins, B. (1992). Landscape ecology of birds breeding in temperate forest fragments. Washington, DC: Smithsonian Instituion Scholarly Press.

Galpern, P., Manseau, M., \& Fall, A. (2011). Patch-based graphs of landscape connectivity: A guide to construction, analysis and application for conservation. Biological Conservation, 144(1), 44-55.

Gómez, J. M. (2003). Spatial patterns in long-distance dispersal of Quercus ilex acorns by jays in a heterogeneous landscape. Ecography, 26(5), 573-584.

Hock, K., \& Mumby, P. J. (2015). Quantifying the reliability of dispersal paths in connectivity networks. Journal of the Royal Society Interface, 12(105).

Holling, C. S. (1992). Cross-scale morphology, geometry, and dynamics of ecosystems. Ecological Monographs, 62(4), 447-502.

Hougner, C., Colding, J., \& Söderqvist, T. (2006). Economic valuation of a seed dispersal service in the Stockholm National Urban Park, Sweden. Ecological Economics, 59(3), 364-374.

Hovestadt, T., Bonte, D., Dytham, C., \& Poethke, H. J. (2012). Evolution and emergence of dispersal kernels-A brief theoretical evaluation. In J. Clobert, M. Baguette, T. G. Benton, \& J. M. Bullock (Eds.), Dispersal ecology and evolution (pp. 211-221). Oxford: Oxford University Press.

IPCC. (2013). Summary for policymakers. Cambridge and New York: Cambridge University Press.

Jump, A. S., \& Peñuelas, J. (2005). Running to stand still: Adaptation and the response of plants to rapid climate change. Ecology Letters, 8(9), 1010-1020.

Kang, W., Lee, D., \& Park, C.-R. (2012). Nest distribution of magpies Pica pica sericea as related to habitat connectivity in an urban environment. Landscape and Urban Planning, 104(2), 212-219.

Kong, F., Yin, H., Nakagoshi, N., \& Zong, Y. (2010). Urban green space network development for biodiversity conservation: Identification based on graph theory and gravity modeling. Landscape and Urban Planning, 95(1/2), 16-27.

Lawler, J. J., Ruesch, A. S., Olden, J. D., \& McRae, B. H. (2013). Projected climate-driven faunal movement routes. Ecology Letters, 16(8), 1014-1022.

Lechner, A. M., Doerr, V., Harris, R. M. B., Doerr, E., \& Lefroy, E. C. (2015). A framework for incorporating fine-scale dispersal behaviour into biodiversity conservation planning. Landscape and Urban Planning, 141, 11-23.

Lindner, M., Fitzgerald, J. B., Zimmermann, N. E., Reyer, C., Delzon, S., van der Maaten, E., ... Hanewinkel, M.
(2014). Climate change and European forests: What do we know, what are the uncertainties, and what are the implications for forest management? Journal of Environmental Management, 146, 69-83.

Littlefield, C. E., McRae, B. H., Michalak, J. L., Lawler, J. J., \& Carroll, C. (2017). Connecting today's climates to future climate analogs to facilitate movement of species under climate change. Conservation Biology, 31(6), 1397-1408.

McCarthy-Neumann, S., \& Ibáñez, I. (2012). Tree range expansion may be enhanced by escape from negative plant-soil feedbacks. Ecology, 93(12), 2637-2649.

McGuire, J. L., Lawler, J. J., McRae, B. H., Nuñez, T. A., \& Theobald, D. M. (2016). Achieving climate connectivity in a fragmented landscape. Proceedings of the National Academy of Sciences, 113(26), 7195-7200.

McRae, B. H., \& Beier, P. (2007). Circuit theory predicts gene flow in plant and animal populations. Proceedings of the National Academy of Sciences, 104(50), 19885-19890.

Milanesi, P., Holderegger, R., Caniglia, R., Fabbri, E., Galaverni, M., \& Randi, E. (2017). Expert-based versus habitat-suitability models to develop resistance surfaces in landscape genetics. Oecologia, 183(1), 67-79.

Nathan, R. (2006). Long-distance dispersal of plants. Science, 313(5788), 786-788.

Nuñez, T. A., Lawler, J. J., Mcrae, B. H., Pierce, D. J., Krosby, M. B., Kavanagh, D. M., ... J., T. J. (2013). Connectivity planning to address climate change. Conservation Biology, 27(2), 407-416.

Pascual-Hortal, L., \& Saura, S. (2006). Comparison and development of new graph-based landscape connectivity indices: Towards the priorization of habitat patches and corridors for conservation. Landscape Ecology, 21(7), 959-967.

Peña-Domene, M., Minor, E. S., \& Howe, H. F. (2016). Restored connectivity facilitates recruitment by an endemic large-seeded tree in a fragmented tropical landscape. Ecology, 97(9), 2511-2517.

Pereira, J., Saura, S., \& Jordán, F. (2017). Single-node vs. multi-node centrality in landscape graph analysis: Key habitat patches and their protection for 20 bird species in NE Spain. Methods in Ecology and Evolution, 8(11), 1458-1467.

Petit, R. J., Hu, F. S., \& Dick, C. W. (2008). Forests of the past: A window to future changes. Science, 320(5882), 1450-1452.

Phillips, S. J., Dudík, M., \& Schapire, R. E. (2017). Maxent software for modeling species niches and distributions (Version 3.4.1). Biodiversity Informatics. Retrieved from biodiversityinformatics.amnh.org/ open_source/maxent

Pons, J., \& Pausas, J. G. (2007). Acorn dispersal estimated by radio-tracking. Oecologia, 153(4), 903-911.

Rayfield, B., Fortin, M.-J., \& Fall, A. (2011). Connectivity for conservation: A framework to classify network measures. Ecology, 92(4), 847-858. 
Rayfield, B., Pelletier, D., Dumitru, M., Cardille, J. A., Gonzalez, A., \& Travis, J. (2016). Multipurpose habitat networks for short-range and long-range connectivity: A new method combining graph and circuit connectivity. Methods in Ecology and Evolution, 7(2), 222-231.

Rolando, A. (1998). Factors affecting movements and home ranges in the jay (Garrulus glandarius). Journal of Zoology, 246(3), 249-257.

Saunders, D. A., Hobbs, R. J., \& Margules, C. R. (1991). Biological consequences of ecosystem fragmentation: A review. Conservation Biology, 5(1), 18-32.

Saura, S., \& Pascual-Hortal, L. (2007). A new habitat availability index to integrate connectivity in landscape conservation planning: Comparison with existing indices and application to a case study. Landscape and Urban Planning, 83(2/3), 91-103.

Saura, S., Vogt, P., Velázquez, J., Hernando, A., \& Tejera, R. (2011). Key structural forest connectors can be identified by combining landscape spatial pattern and network analyses. Forest Ecology and Management, 262(2), 150-160.

Stevenson-Holt, C. D., Watts, K., Bellamy, C. C., Nevin, O. T., \& Ramsey, A. D. (2014). Defining landscape resistance values in least-cost connectivity models for the invasive grey squirrel: A comparison of ap- proaches using expert-opinion and habitat suitability modelling. PLoS One, 9(11).

Thomas, C. D. (2010). Climate, climate change and range boundaries. Diversity and Distributions, 16(3), 488-495.

Urban, D., \& Keitt, T. (2001). Landscape connectivity: A graph-theory perspective. Ecology, 82(5), 1205-1218.

Warton, D. I., Renner, I. W., \& Ramp, D. (2013). Modelbased control of observer bias for the analysis of presence-only data in ecology. PLoS One, 8(11), e79168.

Watts, K., Eycott, A. E., Handley, P., Ray, D., Humphrey, J. W., \& Quine, C. P. (2010). Targeting and evaluating biodiversity conservation action within fragmented landscapes: An approach based on generic focal species and least-cost networks. Landscape Ecology, 25(9), 1305-1318.

Wenny, D. G. (2000). Seed dispersal, seed predation, and seedling recruitment of a neotropical montane tree. Ecological Monographs, 70(2), 331-351.

Wilkinson, D. M. (1997). Plant colonization: Are wind dispersed seeds really dispersed by birds at larger spatial and temporal scales? Journal of Biogeography, 24(1), 61-65.

\section{About the Authors}

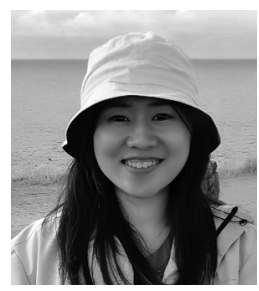

Qiyao Han is a PhD (Architecture) candidate at the School of Natural and Built Environment, Queen's University Belfast. She has a Bachelor's and Master's degree in Landscape Architecture. Her research fields are resilient landscape design and planning and landscape ecology. Currently, her PhD research focuses on mapping and designing urban landscapes for climate-driven migration of trees.

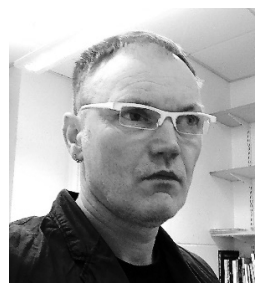

Greg Keeffe is Professor of Architecture and Urbanism and Head of School of Natural and Built Environment. His work focusses on urban sustainability and resilience, particularly focussing on largescale interventions to the city that add productive capacity, particularly through green infrastructures. 